Research, Society and Development, v. 10, n. 2, e39510212896, 2021

(CC BY 4.0) | ISSN 2525-3409 | DOI: http://dx.doi.org/10.33448/rsd-v10i2.12896

\title{
Representações sociais de estudantes de fisioterapia sobre a violência doméstica
}

\section{contra a mulher}

\author{
Social representations of physiotherapy students on domestic violence against women \\ Representaciones sociales de estudiantes de fisioterapia sobre violencia doméstica contra la mujer
}

Recebido: 12/12/2020 | Revisado: 20/02/2021 | Aceito: 20/02/2021 | Publicado: 21/02/2021

Giane Lopes Oliveira

ORCID: https://orcid.org/0000-0002-5133-5594

Universidade Estadual do Sudoeste da Bahia, Brasil

E-mail: giane.lopes07@outlook.com

Juliana Costa Machado

ORCID: http://orcid.org/0000-0002-2258-0718

Universidade Estadual do Sudoeste da Bahia, Brasil E-mail: juliana.costa@uesb.edu.br

Aline Vieira Simões

ORCID: http://orcid.org/0000-0001-5465-4980 Universidade Estadual do Sudoeste da Bahia, Brasil

E-mail: avsimoes@uesb.edu.br

Vilara Maria Mesquita Mendes Pires

ORCID: http://orcid.org/0000-0003-4964-3050 Universidade Estadual do Sudoeste da Bahia, Brasil E-mail: mesquita.vilara@uesb.edu.br

Alba Benemérita Alves Vilela

ORCID: https://orcid.org/0000-0003-2110-1751 Universidade Estadual do Sudoeste da Bahia, Brasil E-mail: abavilela@uesb.edu.br

Vanda Palmarella Rodrigues

ORCID: http://orcid.org/0000-0002-5689-5910

Universidade Estadual do Sudoeste da Bahia, Brasil E-mail: vprodrigues@uesb.edu.br

\begin{abstract}
Resumo
O estudo apresentou como objetivo identificar as representaçoes sociais de estudantes de fisioterapia sobre a violência doméstica contra a mulher. Trata-se de uma pesquisa de natureza qualitativa com uma abordagem descritiva, embasada na Teoria das Representações Sociais, realizada em uma universidade pública no interior da Bahia, com 141 estudantes universitários do curso de graduação em fisioterapia, na qual foi utilizada a técnica de evocação livre de palavras e, posteriormente, foram realizadas entrevistas semiestruturadas com 20 participantes. As evocações foram processadas no software EVOC 2005 e interpretadas através da análise prototípica e da análise de similitude e as entrevistas semiestruturadas pela análise de conteúdo temática. Os estudantes do curso de fisioterapia têm uma representação estruturada negativa sobre a temática, apesar de alguns ter uma visão ampliada sobre a violência doméstica contra a mulher, a maioria deles restringe seu entendimento apenas ao âmbito da agressão física e da violência psicológica, esse fato poderá repercutir para o desenvolvimento de suas práticas de cuidado. Os estudantes de fisioterapia trazem o pensamento que a violência doméstica contra a mulher é permeada pela dominação do poder masculino sobre a mulher, baseado em uma relação de valores patriarcais com definições de papéis sociais e familiares para homens e mulheres. Desta forma, necessita-se de uma abordagem transversal e holística no período de formação, para que esses futuros profissionais possam manejar corretamente os casos de violência doméstica contra a mulher.
\end{abstract}

Palavras-chave: Violência contra a mulher; Formação profissional; Estudantes; Prática profissional; Atenção à saúde.

\begin{abstract}
The study aimed to identify the social representations of physical therapy students about domestic violence against women. It is a qualitative research with a descriptive approach, based on the Theory of Social Representations, conducted at a public university in the interior of Bahia, with 141 university students from the undergraduate course in physiotherapy, in which the evocation technique was used free of words and, subsequently, semi-structured interviews were conducted with 20 participants. The evocations were processed in the EVOC 2005 software and interpreted
\end{abstract}


Research, Society and Development, v. 10, n. 2, e39510212896, 2021

(CC BY 4.0) | ISSN 2525-3409 | DOI: http://dx.doi.org/10.33448/rsd-v10i2.12896

through prototypical analysis and similarity analysis and semi-structured interviews through thematic content analysis. Physiotherapy course students have a negative structured representation on the subject, although some have an expanded view on domestic violence against women, most of them restrict their understanding only to the scope of physical aggression and psychological violence, this fact may impact on the development of their care practices. Physiotherapy students bring the thought that domestic violence against women is permeated by the domination of male power over women, based on a relationship of patriarchal values with definitions of social and family roles for men and women. Thus, a transversal and holistic approach is needed in the training period, so that these future professionals can correctly handle cases of domestic violence against women.

Keywords: Violence against women; Professional training; Students; Professional practice; Health care.

\section{Resumen}

El estudio tuvo como objetivo identificar las representaciones sociales de los estudiantes de fisioterapia sobre la violencia doméstica contra la mujer. Se trata de una investigación cualitativa con enfoque descriptivo, basada en la Teoría de las Representaciones Sociales, realizada en una universidad pública del interior de Bahía, con 141 estudiantes universitarios de la carrera de pregrado en fisioterapia, en la que se utilizó la técnica de evocación libre de palabras. y, posteriormente, se realizaron entrevistas semiestructuradas con 20 participantes. Las evocaciones fueron procesadas en el software EVOC 2005 e interpretadas mediante análisis prototípico y análisis de similitudes y entrevistas semiestructuradas mediante análisis de contenido temático. Los estudiantes del curso de fisioterapia tienen una representación estructurada negativa sobre el tema, aunque algunos tienen una visión ampliada sobre la violencia doméstica contra la mujer, la mayoría restringe su comprensión solo al alcance de la agresión física y la violencia psicológica, este hecho puede impactar en el desarrollo de su prácticas de cuidado. Los estudiantes de fisioterapia traen el pensamiento de que la violencia doméstica contra la mujer está impregnada de la dominación del poder masculino sobre la mujer, basada en una relación de valores patriarcales con definiciones de roles sociales y familiares para hombres y mujeres. Así, se necesita un enfoque transversal y holístico en el período de formación, para que estas futuras profesionales puedan manejar correctamente los casos de violencia doméstica contra la mujer.

Palabras clave: Violencia contra la mujer; Formación professional; Estudiantes; Práctica professional; Atención a la salud.

\section{Introdução}

A violência doméstica contra a mulher vem sendo entendida como um problema de amplitude epidêmica, acarretando os olhares tanto no âmbito público, quanto no meio científico. Não se configura como um novo objeto de estudo, porém de uma problemática advinda de uma matriz histórico-cultural acompanhada por ideias, crenças, heranças e valores, que respaldam a interpretação do fenômeno, até mesmo na esfera da saúde (Acosta et al, 2018).

Trata-se de uma violação dos direitos humanos, atingindo a saúde e integridade física e psíquica das mulheres que vivenciam esse contexto. Destaca-se que na região das Américas, uma a cada três mulheres já vivenciou violência física perpetrada por parceiro íntimo ou violência sexual praticada por outra pessoa, podendo ter repercussões profundas e permanentes para a saúde daquelas agredidas (Organização Mundial da Saúde-OMS, 2015).

Dentre as principais conclusões do Inquérito Demográfico e de Saúde de Ruanda de 2014-2015 (RDHS 5), em um montante nacionalmente representativo de 13.497 mulheres de 15 a 49 anos e 5.585 homens de 15 a 59 anos de 12.793 famílias entrevistadas, foi visto que $33,6 \%$ das mulheres sofreram violência física por parte do parceiro. Grande parte dessa alta prevalência decorre de normas sociais que toleram a violência como parte normal das relações íntimas (National Institute of Statistics of Rwanda-RWANDA, 2015).

Dados do Brasil referentes ao Sistema de Informação de Agravos de Notificação evidenciaram o registro de 223.796 atendimentos de mulheres em situação de violência doméstica, sexual e outras violências no ano de 2015, sendo que duas em cada três mulheres (147.691) demandaram atendimento em alguma unidade de saúde em decorrência da situação de violência. O número de homicídios de pessoas do sexo feminino passou de 3.937 no ano de 2005 para 4762 em 2015 representando uma elevação de $21 \%$ em apenas uma década (Waiselfiz, 2015).

Para o enfrentamento desta problemática é de suma importância que os profissionais, além de atenderem as pessoas em situação da violência, saibam desenvolver métodos para identificar, prevenir e acompanhar os grupos mais vulneráveis, 
além de buscarem organizações em geral que atuem na implementação de políticas públicas inclusivas e protetoras (Machado et al, 2014).

Pesquisas identificaram que alguns profissionais de saúde se sentem despreparados para atuar em situações de violência, em virtude de uma abordagem superficial ou até mesmo inexistente da violência doméstica contra a mulher durante a graduação (Pedroza \& Spink, 2011; Silva, Padoin \& Vianna, 2015). Estudo realizado com estudantes de graduação do curso da área de saúde denotou que o maior impasse apresentado pelos mesmos no que tange ao contexto da violência doméstica contra a mulher, foi o fato de eles se sentirem despreparados na identificação e manejo desse tipo de situação, que pode estar relacionado ao distanciamento desse tema transversal na matriz curricular, evidenciando que ainda há um ensino baseado apenas em um contexto biomédico (Simões et al, 2019).

Nessa direção, a compreensão e as informações dos estudantes universitários de saúde a respeito da violência doméstica advêm de um aspecto informal, através de notícias reportadas pelas mídias e redes sociais, além da falta de preparo para atuar nesse tipo de situação, em virtude da ausência de disciplinas e debates durante seu período de formação, existindo assim um déficit teórico e prático em suas práticas de enfrentamento e cuidado voltados à violência doméstica (Machado et al, 2020).

Diante da dimensão dessa temática que é reconhecida como um problema de saúde pública é fundamental que os futuros profissionais de saúde fisioterapeutas reconheçam as diversas formas de manifestação da violência doméstica contra a mulher, uma vez que muitos irão atuar desde a Atenção Primária à Saúde que constitui a principal porta de entrada para as mulheres que vivenciam o contexto da violência doméstica, até o nível terciário, portanto os mesmos precisam estar aptos a identificar, manejar e encaminhar essas mulheres, devendo assim prestar uma assistência integral e qualificada. Nessa perspectiva, surgiu a questão que norteou o presente estudo: quais as representações sociais de estudantes universitários de fisioterapia sobre a violência doméstica contra a mulher?

A compreensão da representação social recai sobre uma forma de percepção de saber do senso comum, que designa uma forma de pensamento social. São categorias de pensamento prático conduzido para a comunicação, entendimento e o domínio do âmbito social, material e ideal (Jodelet, 1984). Dessa forma, considera-se que a Teoria das Representações Sociais (TRS) como referencial teórico permite entender como as representações sociais dos futuros profissionais de fisioterapia sobre violência doméstica contra a mulher podem direcionar suas práticas de cuidado à mulher em situação de violência doméstica. Nessa direção, o estudo teve como objetivo identificar as representações sociais de estudantes de fisioterapia sobre a violência doméstica contra a mulher.

\section{Metodologia}

Estudo descritivo, de natureza qualitativa com aporte teórico embasado na TRS possibilitando uma melhor apreensão do fenômeno, apoiando-se ainda na abordagem estrutural, também conhecida como Teoria do Núcleo Central, proposta por Jean Claud Abric, em que toda representação está estruturada em volta de um núcleo central (NC) e, no qual este representa sua acepção e fundação interna exteriorizando os ideais coletivos (Abric, 2000).

Uma representação social consiste em uma modalidade de entendimento socialmente formulada e partilhada, com um objetivo prático contribuindo para a construção de uma realidade comum a um conjunto social, além de proporcionar a interpretação desse âmbito social (Jodelet, 2001).

Os participantes da pesquisa foram constituídos por 141 estudantes do Curso de Graduação em Fisioterapia da Universidade Estadual do Sudoeste da Bahia (UESB), Campus de Jequié/BA. Dentre os critérios de seleção dos participantes, 
Research, Society and Development, v. 10, n. 2, e39510212896, 2021

(CC BY 4.0) | ISSN 2525-3409 | DOI: http://dx.doi.org/10.33448/rsd-v10i2.12896

foram incluídos todos os estudantes devidamente matriculados do $1^{\circ}$ ao $10^{\circ}$ período letivo com idade maior ou igual a 18 anos de idade. Foram excluídos os estudantes que estavam afastados em virtude de exercício domiciliar.

Trata-se de um subprojeto aprovado pelo Comitê de Ética e Pesquisa (CEP) da UESB sob o protocolo 3.424 .236 de 28/06/2019 do projeto de pesquisa maior intitulado: "Representações sociais de estudantes universitários sobre violência doméstica" o qual já foi aprovado pelo CEP da UESB sob o protocolo 1.333.812 de 10/11/2015 e CAAE 49741215.9.0000.0055. Os participantes do estudo foram informados sobre os objetivos, justificativa, riscos e benefícios da pesquisa; bem como a garantia do seu sigilo e anonimato a partir da leitura e assinatura pelos participantes do Termo de Consentimento Livre e Esclarecido (TCLE).

A coleta dos dados foi realizada entre os meses de outubro de 2019 a março de 2020 através da técnica de evocação livre de palavras a 141 estudantes, na qual a pesquisadora enunciava o termo indutor "violência doméstica contra a mulher" e o entrevistado era solicitado a falar as primeiras cinco palavras que logo lhe viesse à mente.

Posteriormente foram realizadas entrevistas semiestruturadas a 20 estudantes, que desejassem participar, apoiando-se no roteiro de entrevista que tinha questões abertas que proporcionaram compreender conceitos, valores e práticas sobre a violência doméstica contra a mulher. As entrevistas foram realizadas individualmente, em salas disponíveis na universidade, que garantia a privacidade, contando com o auxílio de um gravador digital, após autorização dos participantes e tiveram em média uma duração de 30 minutos com transcrição na íntegra.

Procurando preservar o anonimato, as evocações dos participantes foram identificadas pela letra "E”, seguidas de números de 1 a 20 (E1, E2, E3, [...], E20), correspondendo à quantidade dos estudantes universitários entrevistados.

O tratamento dos dados gerados pela técnica de evocação livre de palavras foi realizado por meio do software Ensemble de Programmes Pemettant L'Analyse des Evocations (EVOC) versão 2005. O programa foi criado por Pierre Vergès e tem como critérios a frequência e a ordem de aparição dos termos e permite a construção do quadro de quatro casas, composto pelo núcleo central, primeira e segunda periferias e zona de contraste (Sá, 2002).

A partir dos elementos obtidos do quadro de quatro casas, realizou-se a análise de similitude, proposta por Claude Flament, que admite como critério as coocorrências entre as palavras identificadas nos elementos da representação (Sá, 2002). Assim, é calculado o índice de similitude que é o número de coocorrência dos termos dividido pelo número de sujeitos envolvidos, considerando-se apenas os participantes que expressaram duas ou mais palavras dos elementos da representação e então, com os valores obtidos, foi construída a árvore máxima da representação social.

Neste estudo, foi utilizada a técnica de análise de conteúdo modalidade temática para tratamento das informações obtidas através da entrevista semiestruturada. Para tanto, procedeu-se à seguinte operacionalização: a fase de pré-análise com sistematização do corpus, seguida com leituras flutuantes para produzir uma aproximação e vínculo com os registros que foram analisados. A fase de exploração do material e por fim, na fase de tratamento dos dados, inferência e interpretação foi realizado o tratamento de resultados brutos obtidos com a sua interpretação (Bardin, 2011).

Quando novos tipos de argumentos ou assuntos começam a expirar, não acontece em uma mesma entrevista e nem acontece por meio de novos dados coletados através de novas entrevistas, o que significa dizer que houve saturação dos dados (Fontanella et al, 2011) ocorrendo na $16^{\mathrm{a}}$ entrevista nesse estudo. Entretanto, foram realizadas mais quatro entrevistas para garantir a percepção de saturação dos dados. 


\section{Resultados}

Dos 141 estudantes universitários, 116 eram do sexo feminino e 25 do sexo masculino. A idade variou de 17 a 36 anos, predominando a faixa etária dos 20 a 29 anos, com 115 participantes. Quanto ao estado marital, cinco eram casados, 129 eram solteiros, um divorciado, dois mantinham uma união consensual e quatro não preencheram o questionário. Em relação aos respectivos semestres, 20 eram do $1^{\circ}$ semestre, 17 do $2^{\circ}$ semestre, 14 do $3^{\circ}$ semestre, 10 do $4^{\circ}$ semestre, seis do $5^{\circ}$ semestre, seis do $6^{\circ}$ semestre, sete do $7^{\circ}$ semestre, 21 do $8^{\circ}$ semestre, 20 do $9^{\circ}$ semestre e 20 do $10^{\circ}$ semestre.

O corpus formado com as evocações frente ao termo indutor violência doméstica contra a mulher totalizou 705 palavras, sendo 103 diferentes. Em uma escala de 1 a 5, a média das ordens médias de evocação (rang) foi 2,90, a frequência mínima foi 12 e a frequência média, 25. A partir da análise desses dados foi possível obter o quadro de quatro casas (Figura 1).

Figura 1 - Quadro de quatro casas formado pela evocação dos estudantes universitários diante do termo indutor violência doméstica contra a mulher- Jequié, BA, 2019-2020.

\begin{tabular}{|c|c|c|c|c|c|}
\hline \multicolumn{3}{|c|}{ Frequência $>=25 /$ Rang $<2,90$} & \multicolumn{3}{|c|}{ Frequência $>=13 /$ Rang $>=2,90$} \\
\hline & Freq. & Rang & & Freq. & Rang \\
\hline \multirow[t]{3}{*}{ Agressão } & 86 & 2,628 & Dor & 86 & 2,977 \\
\hline & & & Machismo & 45 & 2,956 \\
\hline & & & Medo & 39 & 2,949 \\
\hline \multicolumn{3}{|c|}{ Frequência $<=12 /$ Rang $<2,90$} & \multicolumn{3}{|c|}{ Frequência $<=12 /$ Rang $>=2,90$} \\
\hline & Freq. & Rang & & Freq. & Rang \\
\hline Abuso & 24 & 2,625 & Denuncia & 17 & 3,647 \\
\hline Covardia & 23 & 1,783 & Injustiça & 22 & 3,636 \\
\hline Desrespeito & 17 & 2,588 & Raiva & 12 & 3,250 \\
\hline Homem & 20 & 2,000 & & & \\
\hline Opressão & 13 & 2,615 & & & \\
\hline Violência-psi & gica 24 & 2,79 & & & \\
\hline
\end{tabular}

Fonte: Dados da Pesquisa (2019-2020).

A Figura 1 demonstra como possível elemento central o termo agressão, com alta frequência e mais prontamente evocado; a primeira periferia foi composta pelos elementos dor, machismo e medo que apesar de apresentarem alta frequência foram evocados mais tardiamente; a segunda periferia foi composta pelos termos denúncia, injustiça e raiva, os quais apresentaram baixa frequência e alta ordem média de evocação. Já na zona de contraste os elementos abuso, covardia, desrespeito, homem, opressão e violência psicológica apresentaram baixa frequência, entretanto foram prontamente evocados.

A partir da análise prototípica, foi possível realizar a análise de similitude por coocorrência dos elementos presentes no quadro de quatro casas. A Figura 2 demonstra a árvore máxima de similitude por coocorrência dos estudantes de fisioterapia ao termo indutor violência doméstica contra a mulher, a qual é possível verificar como se ligam os elementos representacionais e formam a estrutura e organização de pensamento desse grupo social sobre o fenômeno. 
Figura 2 - Árvore máxima da análise de similitude por coocorrência das evocações dos Estudantes Universitários frente ao termo indutor Violência Doméstica contra a mulher. Jequié/BA, 2019-2020 (n=141).

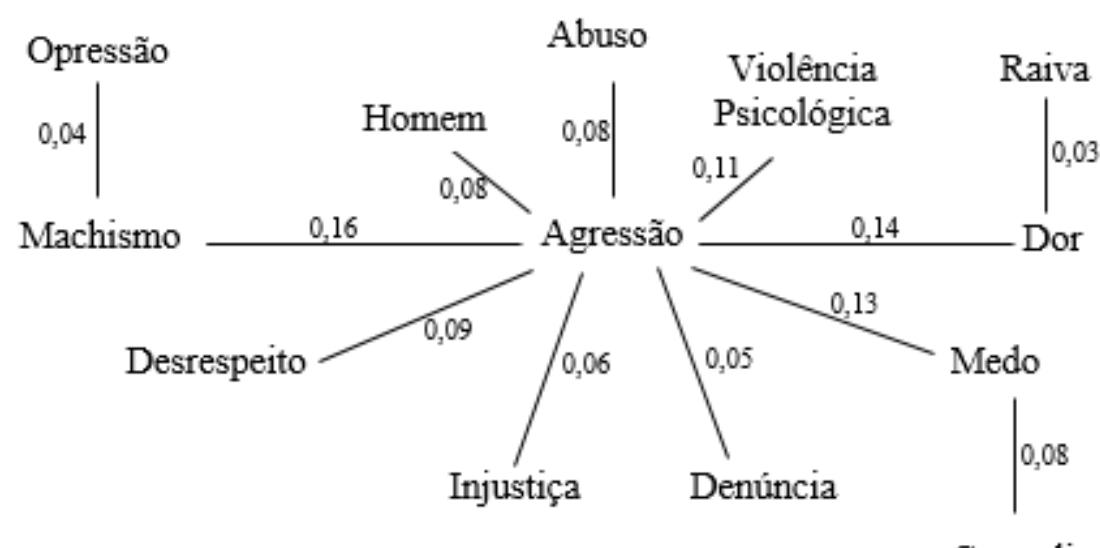

Covardia

Fonte: Dados da Pesquisa (2019-2020).

O provável NC está fortemente relacionado com as conjunções históricas, sociais e conceituais dos indivíduos (Abric, 2000). Ao se estudar as Representações Sociais ordena-se a existência de três dimensões que fundamentam a representação, são elas a conceitual, imagética e atitudinal, sendo que análise dos elementos da árvore máxima da análise de similitude por coocorrência, pode-se instituir essas dimensões.

Assim, na figura 1, observa-se como possível elemento central da representação social o termo agressão. Esse termo reflete sobre a dimensão conceitual e imagética da representação dos estudantes de fisioterapia sobre a violência doméstica contra a mulher, pois demonstra o entendimento e compreensão sobre o agravo e retrata às condutas do agressor que irão comprometer a integridade física, emocional e psicológica das mulheres que vivenciam as agressões.

Ao analisar os números das coocorrências entre os termos enunciados pelos universitários (Figura 2), observa-se que o termo evocado agressão se correlaciona com os termos abuso e violência psicológica, fazendo menção ao campo conceitual da representação. O termo abuso, referido 24 vezes, faz alusão a esse campo conceitual frente a um parecer dos agressores nas situações de violência doméstica contra a mulher, envolvendo vários tipos de comportamentos, seja um abuso físico, sexual, moral ou emocional, bem como a violência-psicológica que faz referência à respeito aos atos violentos à mulher cometidos pelo agressor, que geram consequências ao longo da vida dessas mulheres. Esses achados corroboram com as falas dos entrevistados:

E eu entendo que a violência doméstica contra a mulher é toda a forma de agressão, seja ela física, emocional, moral, social, dentro do ambiente familiar dela, dentro da própria casa dela, onde ela sofre, onde ela enxerga como um ambiente opressor, onde não deveria ser [...] (E1).

É toda agressão que é feita para a mulher, tanto física, quanto verbal, e é tudo que atinge a mulher, que incomoda ela, é uma agressão [...] (E9).

Qualquer violência que vá agredir de algum modo, não só fisicamente, mas psicologicamente, moralmente a saúde física e mental da mulher, de qualquer forma, pode não ser só de relacionamentos amorosos, mas também de alguma forma que vá agredir essa mulher [...] (E18). 
Research, Society and Development, v. 10, n. 2, e39510212896, 2021

(CC BY 4.0) | ISSN 2525-3409 | DOI: http://dx.doi.org/10.33448/rsd-v10i2.12896

Várias, por exemplo, uma das repercussões é ter relacionamento com outro homem, eu acho que pra uma mulher que foi abusada, é muito difícil voltar, porque tem a questão afetiva e tudo mais [...] (E5).

Que a gente acha que é só agressão física, mas é psicológica [...] vai muito além do só o que tá ali, mostrando [...] psicológica, que eu acho que é a que traz mais consequências [...] (E13).

Por sua vez, os elementos localizados na primeira periferia, quadrante superior direito, dor e medo trazem a dimensão afetiva das representações e atuam de forma a integrar as experiências ao núcleo central. Os estudantes representam através da dor e do medo sentimentos da vivência da mulher em situação de violência. A palavra dor faz referência a um sentimento que tanto pode ser relacionado a uma dor física, quanto a uma dor emocional, que geram consequências permanentes à mulher que vive a situação de violência, ou ainda, faz menção ao sentimento de angústia, tristeza e decepção que os estudantes de fisioterapia têm frente ao contexto da violência doméstica contra a mulher e observa-se a partir dos números das coocorrências, que esse termo está fortemente ligado com o NC da representação, que foi o termo agressão.

Tristeza, por causa que eu não entendo como uma pessoa que escolher outra pra viver pra sempre, ou viver por determinada quantidade de tempo, tenha essa coragem de fazer mal a essa outra pessoa que diz $\operatorname{amar}[\ldots](E 17)$.

E medo expressa o conceito que o estudante universitário tem diante de um dos sentimentos que a mulher em contexto de violência venha a ter, ou pode ainda estar relacionado ao sentimento do estudante sobre a possibilidade de passar pela mesma situação.

[...] mas eu acredito que o principal sentimento que eu tenho é medo. Porque hoje em dia é tantos casos que a gente vê, tantas histórias, que apesar de nunca ter acontecido diretamente comigo, faz com que eu me sinta preocupada, porque eu acho que ninguém tá imune a isso [...] o principal sentimento que eu tenho é medo [...] (E20).

Por medo, medo de denunciar justamente por essas leis serem falhas ou brandas demais e o caso se repetir, medo do parceiro, medo de denunciar, de se expor [...] (E18).

Ainda, referente ao campo afetivo, o elemento raiva referente a segunda periferia, quadrante inferior direito, refere-se ao sentimento dos participantes sobre o agressor responsável pela violência doméstica contra a mulher.

E a outra é raiva, de pensar que um homem como eu também, é capaz de executar algo assim e não se dá conta do quão nocivo ele está sendo, não só para aquele indivíduo, para aquela mulher, mas pra ele mesmo, porque ele se descaracteriza enquanto ser humano, então ele deixa a humanidade dele de lado $[\ldots](E 11)$.

Os termos denúncia e injustiça, localizados na segunda periferia, fazem menção à dimensão jurídica no contexto da violência doméstica contra a mulher e apresenta uma função social das representações sobre o agravo, trazendo uma função 
Research, Society and Development, v. 10, n. 2, e39510212896, 2021

(CC BY 4.0) | ISSN 2525-3409 | DOI: http://dx.doi.org/10.33448/rsd-v10i2.12896

pragmática, das práticas sociais, além de fazer uma alusão a uma dimensão prática-consequencial, ou seja, para esses estudantes a prática da denúncia pode gerar consequência às mulheres.

Essas evocações evidenciaram o pensamento dos estudantes universitários tanto sobre o medo das mulheres em denunciar a violência, por diversas questões que envolvem os filhos, medo de recidivas de atos violentos, medo de morrerem pelo fato de acharem que a justiça é falha, pois as medidas protetivas e as leis não são suficientes, o que para os estudantes, esse cenário da violência doméstica gera um contexto de ilegalidade, o que requer estímulo às denúncias tanto para as mulheres, quanto para os profissionais de saúde.

Além disso, a injustiça transmite a ideia de ser um dos possíveis motivos que perpetuam a violência doméstica, como consequência do déficit da atuação de políticas públicas efetivas e imediatas que assegurem a punição ao agressor.

[...] mas acredito sim que tem que intensificar as leis, ou então mostrar para as pessoas que elas têm leis que lhe amparem no caso, melhorar a questão dessa denúncia, [...] desmistificar essa ideia de que "briga de marido e mulher ninguém mete a colher" porque a gente pode sim denunciar, e deve, quando de fato acontece, quando a gente presencia, ouve alguma coisa assim [...] (E20).

[...] e aí por situações psicológicas ou financeiras ela não chegue a denunciar, então nunca que vai ter alguma intervenção diante disso [...] (E16).

Acredito que a justiça é falha, por conta das leis que impedem de que o criminoso fique na cadeia pelo o que ele fez, isso gera um sentimento de impunidade, de que não vai dá nada e volta a ocorrer de novo $[\ldots](E 3)$.

Os elementos localizados na zona de contraste: covardia, desrespeito, homem, opressão, são elementos importantes para os participantes da pesquisa, em relação ao objeto social e fazem parte do campo atitudinal da representação. Os termos opressão, covardia e desrespeito demonstram ser condições atitudinais que motivam o ato violento por parte do agressor, no qual o termo homem diz respeito a esse agressor, aquele que comete os atos violentos.

[...] porque os principais vetores, os principais autores da violência contra a mulher são os homens [...] $(E 1)$.

Eu não sei se isso é um estereótipo, mas ele, o homem, ele é o principal agressor, digamos assim, a figura principal que pratica a violência [...] (E2).

Eu entendo que a violência contra a mulher é um problema de saúde pública que afeta não só a vítima, mas também a família, e todo o contexto social da mulher, que é uma forma de opressão e que pode ser manifesta de várias formas, vários tipos de violência [...] (E15).

Ainda, o elemento machismo faz parte da dimensão atitudinal da representação e remete à figura masculina, de autossuficiência que pode estar relacionado a um contexto histórico e patriarcal, assim, fortemente ligado ao contexto da violência doméstica. 
Research, Society and Development, v. 10, n. 2, e39510212896, 2021

(CC BY 4.0) | ISSN 2525-3409 | DOI: http://dx.doi.org/10.33448/rsd-v10i2.12896

O machismo influencia muito, porque o machismo ele coloca a figura masculina como superior à mulher, e aí dá o direito, se acha no direito, de agredir ou ter a pessoa como a sua propriedade [...] (E8).

Diante do exposto, compreende-se que os estudantes de fisioterapia têm uma representação ordenada sobre a violência doméstica contra a mulher que é delimitada à agressão no qual esse termo organiza a representação social desses indivíduos sobre o objeto estudado.

\section{Discussão}

A violência doméstica contra a mulher é uma problemática de caráter social com elevados índices mundiais, incluindo o Brasil (Souza \& Sabini, 2015) Nesse âmbito, têm-se um relevante impacto na qualidade de vidas das mulheres que vivenciam esse contexto, além de atingir também familiares e a sociedade como um todo (Silva \& Gomes, 2018).

No ano de 2018, foi noticiado pela imprensa brasileira 14.796 casos de violência doméstica em todos os estados da federação brasileira, visto que a maioria das agressões continua a ser perpetrada por parceiros íntimos, correspondendo assim por $58 \%$ dos casos de violência, e os outros $42 \%$ refere-se aos pais, avôs, tios e padrastos. Essas mulheres são cercadas pelos companheiros em um ciclo contínuo de violência, sendo que as principais agressões são de caráter físico e sexual (Mapa da violência contra a mulher, 2018).

Estudo analisou a violência por parceiro íntimo e a violência física do companheiro em um país asiático, a República popular de Bangladesh, no qual o país vive em uma sociedade totalmente patriarcal, em que as mulheres são consideradas como subordinadas aos homens, onde suas responsabilidades recaem sobre seus pais e quando se casam, sobre seus maridos, e são ensinadas a aceitar a violência física praticada pelo cônjuge como parte natural da sua vida, sendo uma prática perpetuada por gerações (Biswas et al, 2017).

No NC da representação o termo agressão se apresenta com uma alta frequência de evocação, e exprime o entendimento dos participantes sobre a principal forma de violência contra a mulher, seja essa agressão física, sexual, psicológica ou moral. Apesar de alguns estudantes do estudo ter uma visão ampliada sobre a violência doméstica contra a mulher, a maioria deles restringe seu entendimento sobre VDCM apenas ao âmbito da agressão física e da violênciapsicológica.

Estudo identificou que a violência física é a forma mais expressiva da violência de gênero, além de reconhecerem a violência psicológica e moral como formas desse tipo de violência, sendo apontados pela pesquisa como as formas mais frequentes e veladas da violência, manifestadas através de humilhações e desrespeito. Portanto, por ser encoberta, é menos percebida e dessa forma, não se tem a concepção por partes dos agressores e das mulheres agredidas que se trata de uma manifestação de violência (Cruz, Espíndula \& Trindade, 2017).

Estudo destacou que grande parte dos profissionais refere o despreparo ao se depararem com casos de violência, considerando uma formação fragmentada, que não visa o ensino em práticas humanitárias com atendimento holístico. Saem de suas graduações com forte predisposição a atuarem sem abordagens sociais e integrais (Oliveira, Almeida \& Morita, 2011).

A partir dessa compreensão dos estudantes acerca do que é a violência doméstica contra a mulher, denota-se uma lacuna na formação profissional dos mesmos frente a essa demanda de atenção nos serviços de saúde. Entretanto, reflete-se que a medida que esses estudantes avançam no curso e aumentam o contato com as usuárias e com as temáticas emergentes, o conceito pode melhor ou se perpetuar. 
Destacou-se ainda em outro estudo a necessidade de incluir conteúdos pontuais e transversais sobre a violência contra as mulheres no currículo de graduação, além da urgência de articulação entre a assistência e o ensino, visto que a formação dos profissionais de saúde é indispensável para uma identificação prévia de mulheres em situação de violência, além de um acolhimento e encaminhamento eficazes (Cuandra et al, 2015).

Dessa forma, é imprescindível que os estudantes de fisioterapia, assim como os demais da área de saúde saibam identificar e manejar suas práticas de cuidado no que concerne aos casos de mulheres em situação de violência doméstica. A saber, um estudo realizado com estudantes universitários demonstrou que os discentes não compreendem que a violência faça parte de suas condutas profissionais, ignorando assim a visão holística de um indivíduo (Cuandra et al., 2015).

Um estudo realizado com estudantes universitários de fisioterapia e enfermagem da Turquia mostrou que esses estudantes identificam a violência doméstica contra a mulher como uma forma generalizada na sociedade e que o homem, como principal agressor dessa violência não pode se apropriar de razões ou justificativas para os atos violentos, além de que os estudantes também citaram que se sentem incomodados com essa problemática, o que nesse presente estudo, os estudantes apontaram o sentimento de raiva quando abordados sobre a temática (Aktas, 2016).

Para tanto, o estudo identificou ainda que é necessária uma melhor conscientização desses estudantes sobre a temática em questão, com programas educacionais que estimulem a informação, orientação e prevenção desses universitários frente à violência doméstica contra a mulher (Aktas, 2016).

O termo machismo que nesse contexto está atrelado ao homem está associado à violência de gênero que é permeada pela dominação do poder masculino sobre a mulher, baseado em uma relação de valores patriarcais com definições de papéis sociais e familiares para homens e mulheres, em que o machismo é conceituado como um dos principais elementos precipitadores desse tipo de violência, e a socialização de gênero denotada como o principal enfoque à prevenção do fenômeno (Bandeira, 2014; Cruz, Espíndula \& Trindade, 2017).

No que tange ao contexto doméstico e cuidados com os filhos coube no cenário social atribuir esses papéis à mulher, contribuindo assim para uma cultura de apropriação masculina sobre o corpo e o comportamento que as mulheres devem se sujeitar (Prado \& Silva, 2017).

A violência doméstica contra a mulher apontada nesse estudo como parte do campo atitudinal através dos termos opressão, desrespeito e covardia por parte do homem, e como parte do campo conceitual através do elemento abuso, gera várias consequências na vida dessas mulheres, como a dor, física ou emocional, e o medo. Estudo realizado com mulheres que sofreram violência conjugal versa nas evocações dessas mulheres que as repercussões dos atos violentos vão desde marcas visíveis como hematomas ou aquisição de doenças sexualmente transmissíveis, mudanças nos níveis pressóricos por estresse, até repercussões emocionais, como medo, tristeza, depressão, baixo-autoestima, síndrome do pânico (Carneiro et al, 2017).

Nota-se através desse estudo que os estudantes de fisioterapia ao evocarem sobre a denúncia e a injustiça no âmbito da violência doméstica contra a mulher, fazem menção ao campo jurídico, no que se refere ao medo das mulheres em denunciar seu agressor por diversos fatores, bem como a continuação da violência por causa das falhas na justiça.

Um estudo corrobora com esses achados, ao evidenciar que muitas mulheres a princípio denunciam o seu agressor, porém os fatores que envolvem o contexto familiar, os filhos, a dependência emocional ou financeira do marido que é o agressor, impulsionam a desistência da denúncia. Nesse sentido, é citado que os profissionais da área de saúde devem oferecer uma melhor assistência a essas mulheres que sofreram agressão, com um melhor preparo na atuação, prevenção e encaminhamento (Jong, Sadala \& Tanaka, 2008).

Ainda, outro estudo menciona que no campo jurídico muitos profissionais compreendem pouco sobre a violência de gênero, no qual há um machismo institucionalizado que limita o incremento de políticas de gênero que beneficiem a promoção 
Research, Society and Development, v. 10, n. 2, e39510212896, 2021

(CC BY 4.0) | ISSN 2525-3409 | DOI: http://dx.doi.org/10.33448/rsd-v10i2.12896

dos direitos das mulheres e a igualdade de gênero, o que essa situação institucionalizada resulta na culpabilidade sobre as mulheres, que muitas vezes não sabem o que querem, e colocam a denúncia dessas mulheres em dúvida, ofertando um atendimento sem acolhimento e humanização (Pasinato, 2015).

\section{Conclusão}

O estudo mostrou que as representações sociais dos estudantes universitários de fisioterapia sobre a violência doméstica contra a mulher estão centradas na agressão, porém com um entendimento limitado na agressão física, apesar de alguns estudantes compreenderem a violência psicológica como uma das formas de violência doméstica.

Ressalta-se que os estudantes detêm o conhecimento sobre a temática, apesar da visão reducionista, com uma conotação negativa a respeito da violência doméstica contra a mulher, identificada através do campo atitudinal, o que poderá repercutir para o desenvolvimento de suas práticas de cuidado, contudo é necessário que esses estudantes tenham um entendimento mais ampliado sobre o assunto, para que de fato a assistência seja eficaz.

Desse modo, além de favorecer o desenvolvimento humano com a finalidade de propiciar o enfrentamento da violência doméstica contra a mulher, esses futuros profissionais da saúde precisam basear suas práticas de cuidado visando à integralidade, equidade e universalidade, a fim de propiciar uma assistência biopsicossocial a essas mulheres, com domínio na identificação dos casos e efetividade nos encaminhamentos.

Faz-se ainda necessário que as universidades promovam espaços para discussões sobre esse eixo temático, com introdução de conteúdos específicos e transversais sobre a violência doméstica contra a mulher no currículo de graduação de fisioterapia, no intuito de melhor capacitá-los para uma futura abordagem coerente e eficaz.

Como limitação do estudo, destaca-se a escassez do tema em questão relacionado aos estudantes universitários da área de saúde e com base nisso, instiga-se a elaboração de estudos que possibilitem analisar as representações dos estudantes universitários de saúde, para um melhor manejo de sua prática profissional sobre o tema em questão.

\section{Agradecimentos}

Agradecemos ao Grupo de Pesquisa Violência, Saúde e Cultura de Paz (GPVIO) e ao Grupo de Estudos Filosóficos em Representações Sociais da Universidade Estadual do Sudoeste da Bahia por todos os momentos de ensinamentos de excelência e investimentos sobre a temática.

\section{Referências}

Abric, J. C. (2000). A abordagem estrutural das representações sociais. Em: Moreira, A. S. P. \& Oliveira, D. C. (orgs.). Estudos interdisciplinares de representação social. $\mathrm{AB}$.

Acosta, D. F., Gomes, V. L. O., Oliveira, D. C., Marques, S. C. \& Fonseca, A. D. (2018). Representações sociais de enfermeiras acerca da violência doméstica contra a mulher: estudo com abordagem estrutural. Revista Gaúcha de Enfermagem, 39, e61308.

Aktaş, D. (2016). Attitudes of University Students Towards Domestic Violence Against Women. Clin Invest Med, 39(6), S173-S178.

Bandeira, L. M. (2014). Violência de gênero: a construção de um campo teórico e de investigação. Sociedade e estado, 29(2), 449-469.

Bardin, L. (2011). Análise de conteúdo. Edições 70.

Biswas, R. K., Rahman, N., Kabir, E. \& Raihan, F. (2017). Women's opinionon the justification of physical spousal violence: A quantitative approach to model the most vulnerable householdsin Bangladesh. PLOS ONE, 12(11), 1-13.

Carneiro, J. B., Gomes, N. P., Estrela, F. M., Santana, J. D., Mota, R. S. \& Erdmann, A. L. (2017). Violência conjugal: repercussões para mulheres e filhas(os). Escola Anna Nery, 21(4), e20160346. 
Research, Society and Development, v. 10, n. 2, e39510212896, 2021

(CC BY 4.0) | ISSN 2525-3409 | DOI: http://dx.doi.org/10.33448/rsd-v10i2.12896

Cruz, S. T. M., Espindula, D. H. P. \& Trindade, Z. A. (2017). Violência de gênero e seus autores: representações dos profissionais de saúde. Psico-USF, 22(3), 555-567.

Cuandra, A. R. (2015). Percepção de estudantes de enfermagem sobre violência do parceiro: conhecimentos, crenças e função profissional. Revista LatinoAmericana de Enfermagem, 23(3), 527-534.

Fontanella, B. J. B., Luchesi, B. M., Saidel, M. G. B., Ricas, J., Turato, E. R. \& Melo, D. G. (2011). Amostragem em pesquisas qualitativas: proposta de procedimentos para constatar saturação teórica. Caderno de. Saúde Pública, 27(2), 388-394.

Jodelet, D. (2001). As representações sociais. UERJ.

Jodelet, D. (1984). Representation sociale: phénomènes, concepts et théories. In: Moscovici, S. (org.). Psychologie Sociale (pp. 357-378). PUF.

Jong, L. C., Sadala, M. L. A. \& Tanaka, A. C. D'A. (2008). Desistindo da denúncia ao agressor: relato de mulheres vítimas de violência doméstica. Revista da escola de enfermagem da USP, 42(4), 744-751.

Machado, J. C., Silva, L. R., Simões, A. V., Pires, V. M. M. M., Rodrigues, V. P. \& Vilela, A. B. A. (2020). Domestic violence as a cross-cutting theme in health professional training. Research, Society and Development, 9(7),1-15. e152973917.

Machado, J. C., Rodrigues, V. P., Vilela, A. B. A., Simões, A. V., Morais, R. L. G. L. \& Rocha, E. N. (2014). Intrafamily violence and actions strategies of the Family Health team. Saúde e Sociedade, 23(3), 828-840.

Mapa da violência contra a mulher 2018. (2018). Comissão de defesa dos direitos da Mulher. Câmera dos Deputados. Brasil. http://cnti.org.br/html/Smulher/2019/mapaviolencia2019.pdf.

National Institute of Statistics of Rwanda-RWANDA. (2015). National Institute of Statistics of Rwanda. Demographic and Health Survey [DHS] 2014/2015 Key findings. Kigali.

Oliveira, C. C., Almeida, M. A. S. \& Morita, I. (2011). Violência e saúde: concepções de profissionais de uma Unidade Básica de Saúde. Revista brasileira de educação médica, 35(3), 412-420.

Organização Mundial da Saúde -OMS. (2015). Organização Pan-Americana Da Saúde. Estratégia e plano de ação para o reforço do sistema de saúde para abordar a violência contra a mulher. Washington DC: Organização Mundial da Saúde.

Pasinato, W. (2015). Acesso à justiça e violência doméstica e familiar contra as mulheres: as percepções dos operadores jurídicos e os limites para a aplicação da Lei Maria da Penha. Revista direito GV, 11(2), 407-428.

Pedrosa, C. M. \& Spink, M. J. P. (2011). A violência contra mulher no cotidiano dos serviços de saúde: desafios para a formação médica. Saúde e Sociedade, 20(1), 124-135.

Prado, V. M. \& Silva, E. M. O. (2017). Núcleo de atenção ao homem como espaço de reconstrução de masculinidades agressoras. Barbarói, 50, $245-262$.

SÁ, C. P. (2002). Núcleo central das representações sociais. Vozes.

Silva, C. D. \& Gomes, V. L. O. (2018). Violência contra a mulher: dimensões representacionais de discentes de enfermagem. Revista de Enfermagem do Centro-Oeste Mineiro, 8, e2528.

Silva, E. B., Padoin, S. M. M. \& Vianna, L. A. C. (2015). Mulher em situação de violência: limites da assistência. Ciência e saúde coletiva, 20(1), $249-258$.

Simões, A. V., Machado, J. C., Soares, I. G. B., Rodrigues, V. P., Pires, V. M. M. M. \& Penna, L. H. G. (2019). Identificação e conduta da violência doméstica contra a mulher sob a ótica dos estudantes universitários. Enfermería Actual de Costa Rica, 37, 95-109.

Souza, T. M. C. \& Sabini, K. (2015). Mas o que é o amor? Representações sociais em mulheres em contexto de violência doméstica. Perspectivas em Psicologia, 19(1), 162-178.

Waiselfisz, J. J. (2015). Mapa da violência 2015: homicídios de mulheres no Brasil. http://www.onumulheres.org.br/wpcontent/uploads/2016/04/MapaViolencia_2015_mulheres.pdf. 